\title{
Cannabinoids and orthopedic surgery: a systematic review of therapeutic studies
}

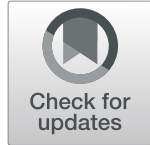

Bradley J. Vivace ${ }^{1,2^{*}}$ (D), Allyson N. Sanders ${ }^{1}$, Steven D. Glassman², Leah Y. Carreon², Joseph L. Laratta ${ }^{2}$ and Jeffrey L. Gum²

\begin{abstract}
Background: Recent work has shed light on the potential benefits of cannabinoids for multimodal pain control following orthopedic procedures. The objective of this review was to summarize the available evidence of analgesic and opioid-sparing effects cannabinoids have in orthopedic surgery and identify adverse events associated with their use.

Methods: A systematic review of the literature using Preferred Reporting Items for Systematic Reviews and MetaAnalyses (PRISMA) guidelines including PubMed, EMBASE, MEDLINE, PsycINFO, and Google Scholar was performed to include all primary, therapeutic studies published on the use of cannabis, and cannabis-derived products in orthopedic surgery.

Results: The literature review returned 4292 citations. Thirteen publications were found to meet inclusion criteria. Four randomized controlled trials were evaluated while the remaining studies were of quasi-experimental design.

Conclusion: Research on cannabinoids in orthopedic surgery is mostly of a quasi-experimental nature and is mainly derived from studies where orthopedics was not the primary focus. The overall results demonstrate potential usefulness of cannabinoids as adjunctive analgesics and in mitigating opioid use. However, the current evidence is far from convincing. There is a need to produce rigorous evidence with well-designed randomized controlled trials specific to orthopedic surgery to further establish these effects.
\end{abstract}

Keywords: Cannabinoids, Orthopedic surgery, Analgesia, Opioids, Arthroplasty, Multimodal pain control

\section{Background}

Cannabinoids represent an area of emerging research amidst legislative change [1]. A cursory search for "medical cannabis" reveals over half of the 9057 citations indexed in the United States (U.S.) National Library of Medicine are from the last 5 years [2]. Cannabinoids are

\footnotetext{
* Correspondence: bjviva01@louisville.edu

This review was conducted in conjunction with Norton Leatherman Spine Center and University of Louisville School of Medicine. Databases utilized for data gathering were provided by Kornhauser Health Sciences Library, associated with University of Louisville School of Medicine located in Louisville, KY.

'University of Louisville School of Medicine, 500 South Preston Street, Louisville, KY, USA

${ }^{2}$ Norton Leatherman Spine Center, 210 E Gray Street, Suite 900, Louisville, KY, USA
}

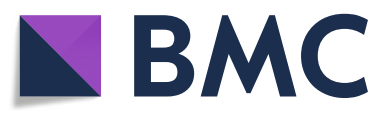

( The Author(s). 2021 Open Access This article is licensed under a Creative Commons Attribution 4.0 International License, which permits use, sharing, adaptation, distribution and reproduction in any medium or format, as long as you give appropriate credit to the original author(s) and the source, provide a link to the Creative Commons licence, and indicate if changes were made. The images or other third party material in this article are included in the article's Creative Commons licence, unless indicated otherwise in a credit line to the material. If material is not included in the article's Creative Commons licence and your intended use is not permitted by statutory regulation or exceeds the permitted use, you will need to obtain permission directly from the copyright holder. To view a copy of this licence, visit http://creativecommons.org/licenses/by/4.0/. The Creative Commons Public Domain Dedication waiver (http://creativecommons.org/publicdomain/zero/1.0/) applies to the data made available in this article, unless otherwise stated in a credit line to the data. (FDA) for recalcitrant chemotherapy-associated nausea and vomiting [3], acquired immunodeficiency syndromerelated anorexia [4], and certain forms of epilepsy [5]. Outside of the USA, an oral solution of delta-9tetrahydrocannabinol (THC) and cannabidiol (CBD) is indicated for refractory multiple sclerosis-associated spasticity [6]. The use of cannabinoids has been investigated in other applications including chronic pain, appetite stimulation, glaucoma, and anxiety [7]. The effects of these compounds have been studied to a lesser extent in orthopedic surgery [8].

Madden et al. covered the use of cannabinoids within orthopedic surgery in their 2018 systematic review 
appraising the literature through 2017 [8]. Since this time, there has been evidence attesting to the benefit of cannabinoids on post-operative recovery and reduction in morphine use following orthopedic procedures [9]. Given the current trend of widespread opioid misuse within the USA [10], this potential to limit narcotic use is promising. Legality has continued to expand [1] and the popularity of cannabinoids has increased where $14 \%$ of Americans in 2019 used CBD products, most commonly for pain [11]. The objective of this review was to summarize the available evidence of analgesic and opioid-sparing effects cannabinoids have within orthopedic surgery and identify adverse events $(\mathrm{AE})$ associated with their use.

\section{Methods}

Guidelines from Preferred Reporting Items for Systematic Reviews and Meta-Analyses Protocols (PRISMA) and PRISMA checklist of recommended items to include in a systematic review were utilized in the construction of this systematic review [12] (Additional file 1: PRISMA Checklist).

\section{Search strategy}

On March 1st, 2020, the databases EMBASE, PubMed, Ovid MEDLINE, PsycInfo, and Google Scholar were queried. Search terms for orthopedic surgery included "orthopaedic surgery," "spine surgery," "orthopaedic procedures," "osteoarthritis," "musculoskeletal disease," and "arthroplasty." These terms were combined with search terms for cannabinoids that included "cannabinoids," "medical cannabis," "cannabis," "tetrahydrocannabinol," and "cannabidiol." Search terms for the PubMed database can be seen in Fig. 1. Other databases were queried in similar fashion (Fig. 1)

\section{Eligibility criteria}

Only primary works of interventional design were considered. Articles combining the therapeutic use of cannabinoids and any subspecialty of orthopedic surgery or conditions common to the field such as fractures, osteoarthritis, and back pain were included. Case reports were excluded, as were non-English and preclinical studies.

\section{Study selection}

A title review was performed of all citations found in each database independently. Duplicate citations were removed, and the abstracts were reviewed. The remaining studies underwent full text review, where each was read individually by at least two of the authors. The review process was performed by BJV and ANS. All disputes of inclusion were settled with the senior authors.

\section{Data extraction and synthesis}

The following data were gathered: study design, population, intervention, control, analgesic effect, differences in opioid use, and AEs. Management of data was done with an electronic chart in which all extracted data was listed by study and utilized for the writing of the manuscript.

\section{Appraisal of evidence}

Evidence of each study was evaluated utilizing the Grading of Recommendations of Assessment, Development, and Evaluation (GRADE) criteria [13] and therapeutic level of evidence was assigned as outlined in the Journal of Bone and Joint Surgery [14]. Bias was assessed with the Revised Cochrane risk-of-bias tool for randomized trials (RoB 2) in randomized controlled trials (RCTs); crossover trials were evaluated with the RoB2 tool specific for crossover trials [15]. The Risk of Bias In NonRandomized Studies-of Interventions (ROBINS-I) [16] tool was used to assess bias in comparative nonrandomized studies. Given the inherent biases found

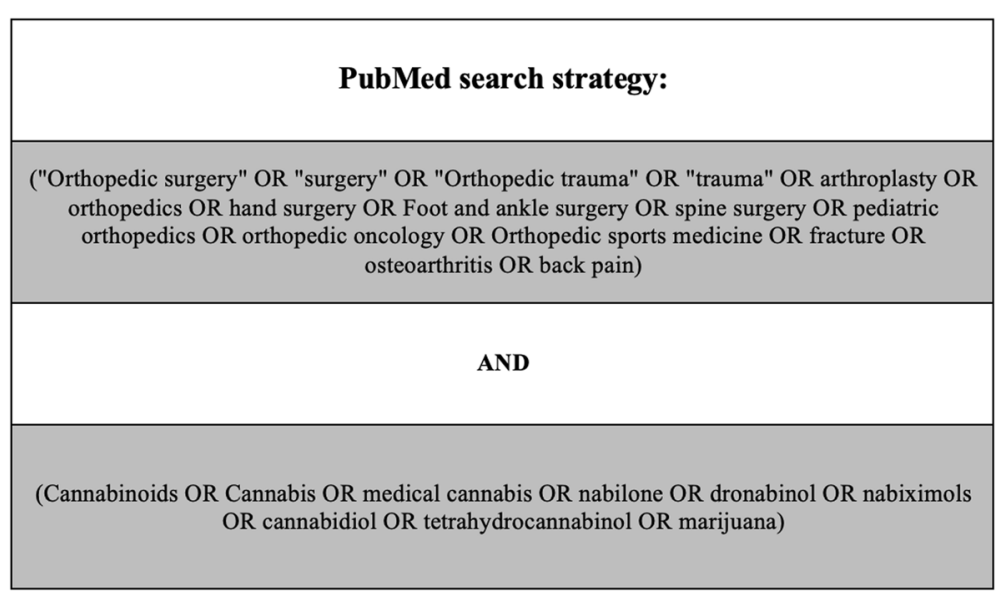

Fig. 1 Search terms for the PubMed database. These are the search terms that were used to perform the query of the PubMed database 
with case series designs, studies without comparative groups were not assessed for bias. Bias was assessed contemporaneously by BJV and ANS.

\section{Results}

The search produced a total of 4292 titles, and 13 publications met our inclusion criteria. The process in which these 13 references were obtained is tabulated in the PRISMA flowsheet depicted by Moher and colleagues [12] (Fig. 2).

\section{Design}

Of the 13 studies, four were RCTs [17-20]. Nine were quasi-experimental in design. This included two of cohorts $[9,21]$, three crossovers [22-24], one dose escalation trial [25], and three case series [26-28]. One cohort was retrospective [9] and the other was prospective [21]. Two crossovers were open label [23, 24], while one blinded and randomized the interventions and placebo, but only enrolled subjects in the crossover portion if they benefited during an anteceding, open label two week run-in with THC/CBD [22].

\section{Appraisal of evidence}

No studies were given a high level of evidence via GRADE. Five were evaluated as moderate evidence [17$20,25]$, three as low evidence $[9,21,22]$, and five as very low [22-24, 26-28]. Regarding therapeutic level of evidence, four provided level I evidence [17-20], two level II evidence [21, 25], one level III evidence [9], and six studies provided level IV evidence [22-24, 26-28] (Table 1). Among RCTs, one was found to have a high risk of bias due to concerns of the randomization process yielding
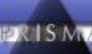

PRISMA 2009 Flow Diagram
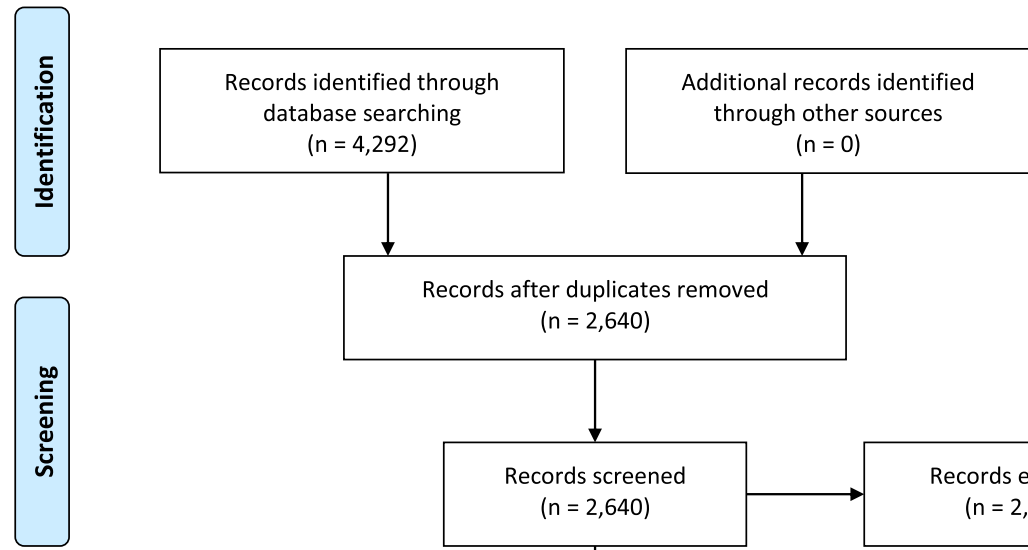

Records after duplicates removed $(n=2,640)$
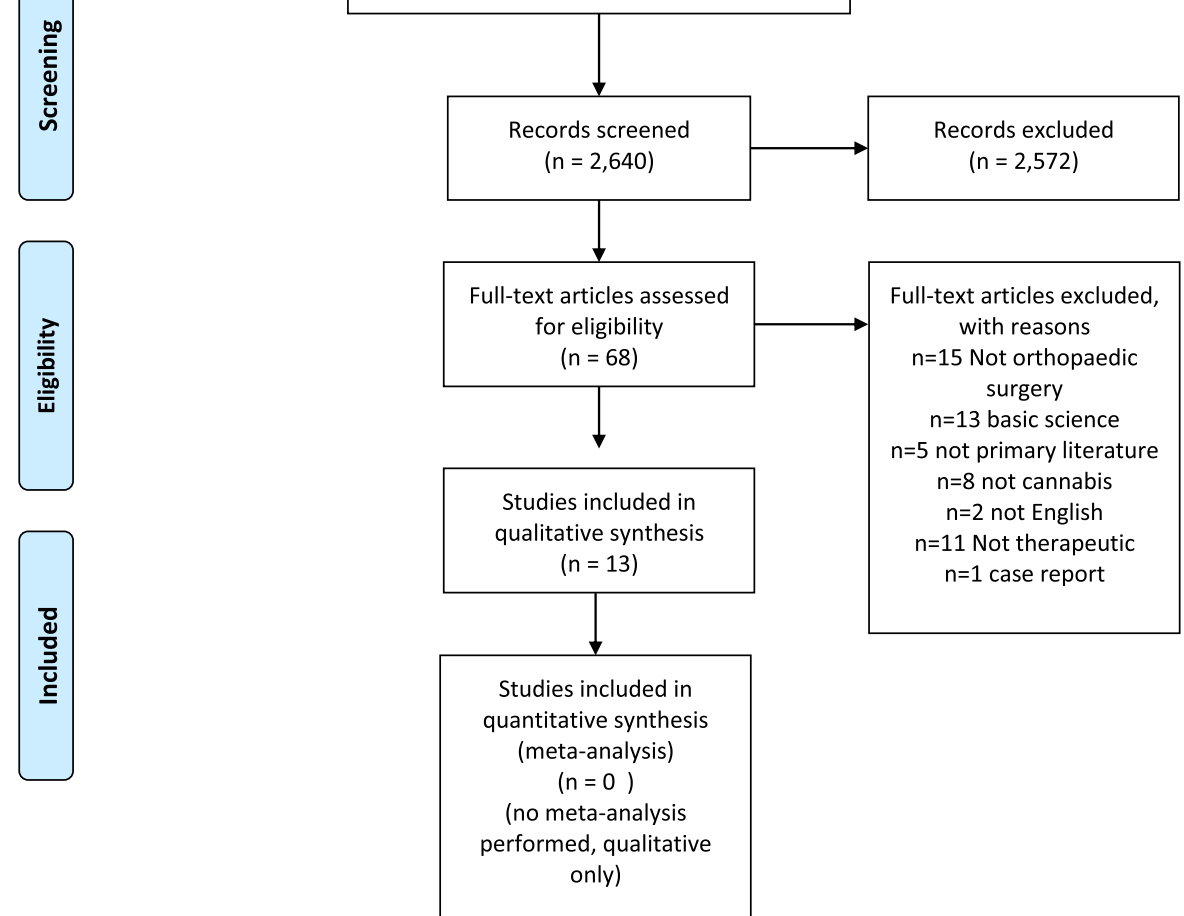

Fig. 2 PRISMA flow diagram presenting the systematic review process used in this study. This flow diagram tabulates the process of how the references utilized in this study were obtained 


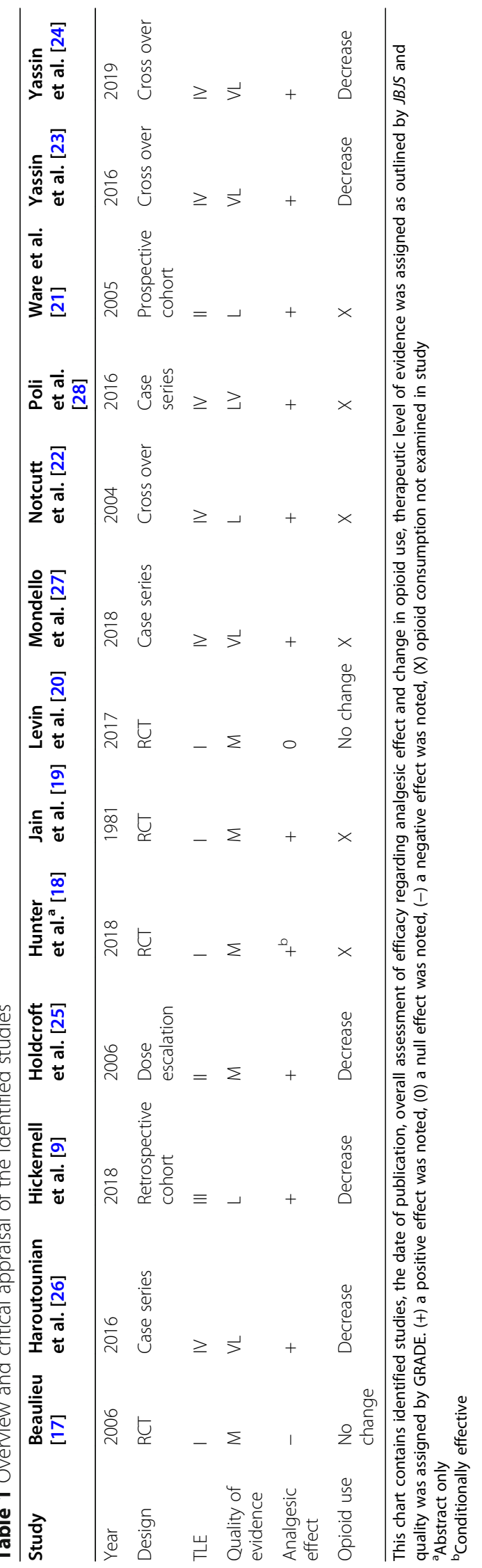


disparate comparative groups [17], two of some concern for bias [18, 19], and one of low risk of bias [20]. Across crossover studies, some concern of bias was found in one [22], while both studies completed by Yassin were judged to be of high risk of bias given their open-label, nonrandomized design [23, 24]. All three non-randomized comparative trials were found to be of moderate risk of bias $[9,21,25]$ (Table 2).

\section{Population}

Five studies were in the acute perioperative setting [9, $17,19,20,25]$, including two post THA or TKA $[9,17]$, one in fracture care [19], and two unspecified orthopedic procedures $[20,25]$. The remaining eight studies involved patients with chronic pain from arthritis $[18,21$, $22,28]$, low back pain [23, 24, 26, 27], and chronic postsurgical pain [22, 27]. Jain et al. included $>90 \%$ of male subjects [19], while a female preponderance of greater than $75 \%$ of subjects was noted in four studies [17, 20, $24,25]$, with one exclusively female [20].

\section{Intervention}

A multiplicity of interventions was used. Oral caplets of cannabinoids were the most common, comprising four studies $[9,17,20,25]$. Two exclusively utilized the combustion or vaporization of cannabis [23, 24]. Liquid oral administration either sublingual or THC/CBD suspension was used in three studies [22, 27, 28]. One utilized transdermal CBD gel [18], while another used intramuscular levonantradol [19]. Two allowed for patient choice of administration resulting in mixed delivery; most commonly smoked cannabis $[21,26]$. The dose, frequency, and potency of cannabinoid varied widely and can be seen by study in Table 3 .

\section{Control}

Six studies had separate control groups. Among RCTs, one study included a positive control of ketoprofen and negative placebo [17], while the remaining three involved only identical placebo as negative control [1820]. Only two of the non-randomized trials involved a parallel control group: one involved subjects characteristically matched to the intervention group [9] and the other had multiple, statistically significant differences among subjects between intervention and control [21]. Information on control groups is further tabulated in Table 3,

\section{Analgesic effects}

All studies evaluated analgesic effect, using different measures. Most commonly reported were $0-10$ point analog scales [17-24, 28], then Brief Pain Index (BPI) [23, 26, 27], McGill pain questionnaire [21], and 0-4 point verbal scales $[19,25]$. Eleven found a positive effect $[9,18,19,21-28]$, one found no effect [20], and one a negative effect [17]. RCTs reported mixed efficacy: two demonstrated mitigation of pain $[18,19]$, one no effect [20], and one increased pain [17]. In the perioperative setting, cannabinoids were found to be efficacious in three studies $[9,19,25]$. Cannabinoids were found effective in all studies evaluating chronic pain of orthopedic etiology [18, 21-24, 26-28]. However, the one RCT in this group found statistical significance only among men [18]. THC or THC in combination with $\mathrm{CBD}$ was found to have statistical significance in the reduction of pain vs. placebo, where CBD alone was not statistically significant vs. placebo [22]. In studies that evaluated different dosages of the same cannabinoid, the responses to these differing doses varied across reports. One study reported an exacerbation of pain with increased doses of nabilone (2 $\mathrm{mg}$ vs. $1 \mathrm{mg}$ ) [17], and another found the pain control provided by $2.5 \mathrm{mg}$ of levonantradol was significantly better than $3 \mathrm{mg}$ [19]. A null effect was also reported with increased dosages, 500 $\mathrm{mg} /$ day of topical CBD was not associated with significantly increased analgesia vs. $250 \mathrm{mg} /$ day in the setting of knee osteoarthritis [18]. In contrast, the analgesic effect of $10 \mathrm{mg}$ and $15 \mathrm{mg}$ of oral CBD/THC was found superior to $5 \mathrm{mg}$ in the one dose escalation trial [25].

\section{Opioid-sparing effects}

Seven studies quantified the effect of cannabinoids upon opioid use [9, 23-26], including two RCTs [17, 20]. Five noted a decrease in opioids administered [9, 23-26], while both RCTs reported no change $[17,20]$. In the perioperative setting, no change in morphine equivalents given was found by two $[17,20]$, a reduction of total morphine equivalents given across a hospital stay was found in one [9], and a dose-dependent response in the reduction of rescue analgesia in another [25]. Two studies noted complete cessation of opioid use in the majority of subjects with chronic pain with six [26] to twelve [23] months of cannabinoid use (Table 4).

\section{Adverse events}

All studies sought to evaluate for AEs, one as the primary outcome [21]. Among six studies with parallel control groups, one found no AEs in the perioperative setting [9] and another no difference in severe AEs over 12 months [21]. Five found significantly greater rates of AEs in their cannabinoid group, including sedation [17, 19], transiently decreased muscular coordination [20], headache and application site xerosis [18], decreased lung function, and upper respiratory complaints [21]. Among all studies, xerostomia [17, 19, 20, 22, 25, 27], headache $[18,20,21,27]$, and drowsiness or sedation $[17,19-22,25-28]$ were particularly common. Euphoria or dysphoria occur in three studies [21], and was more common in THC containing preparations vs. CBD or 


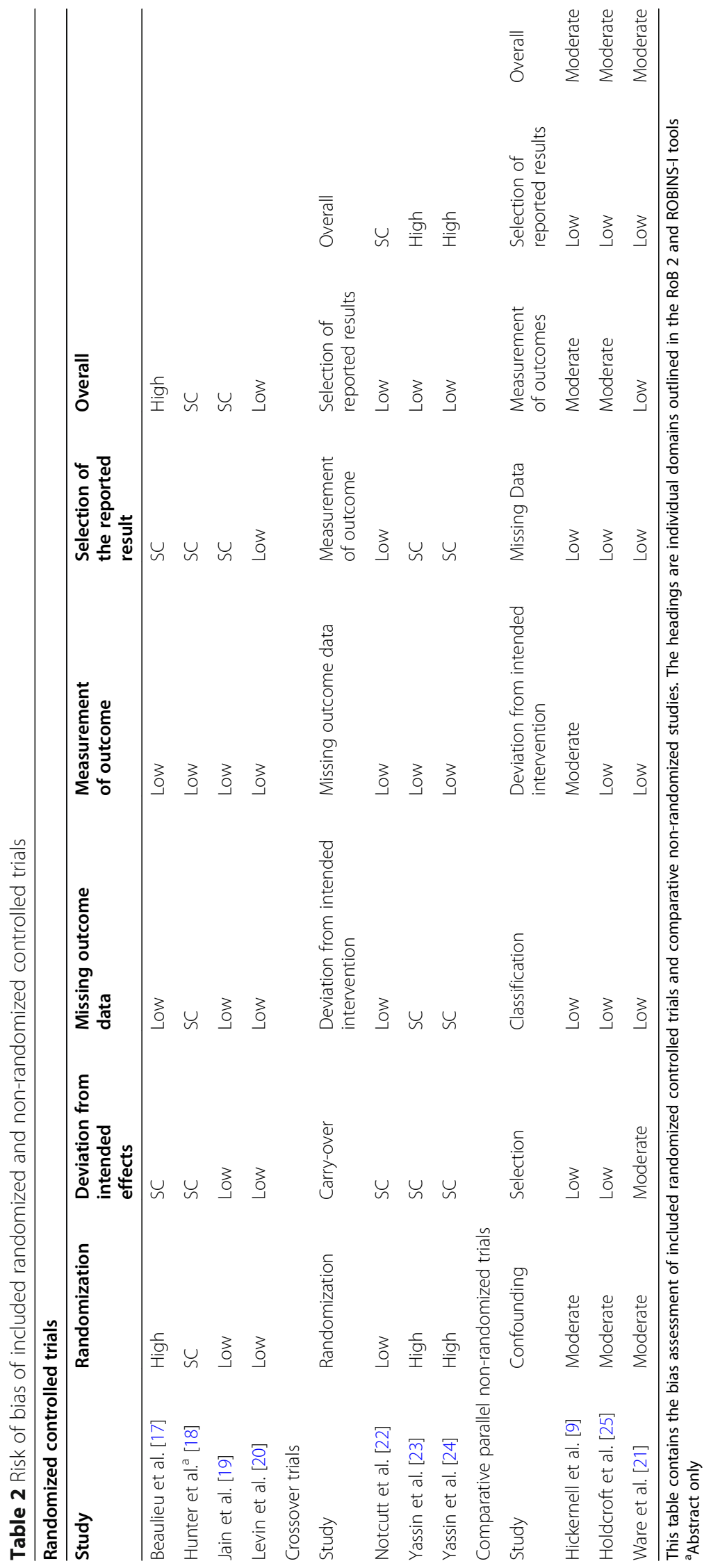




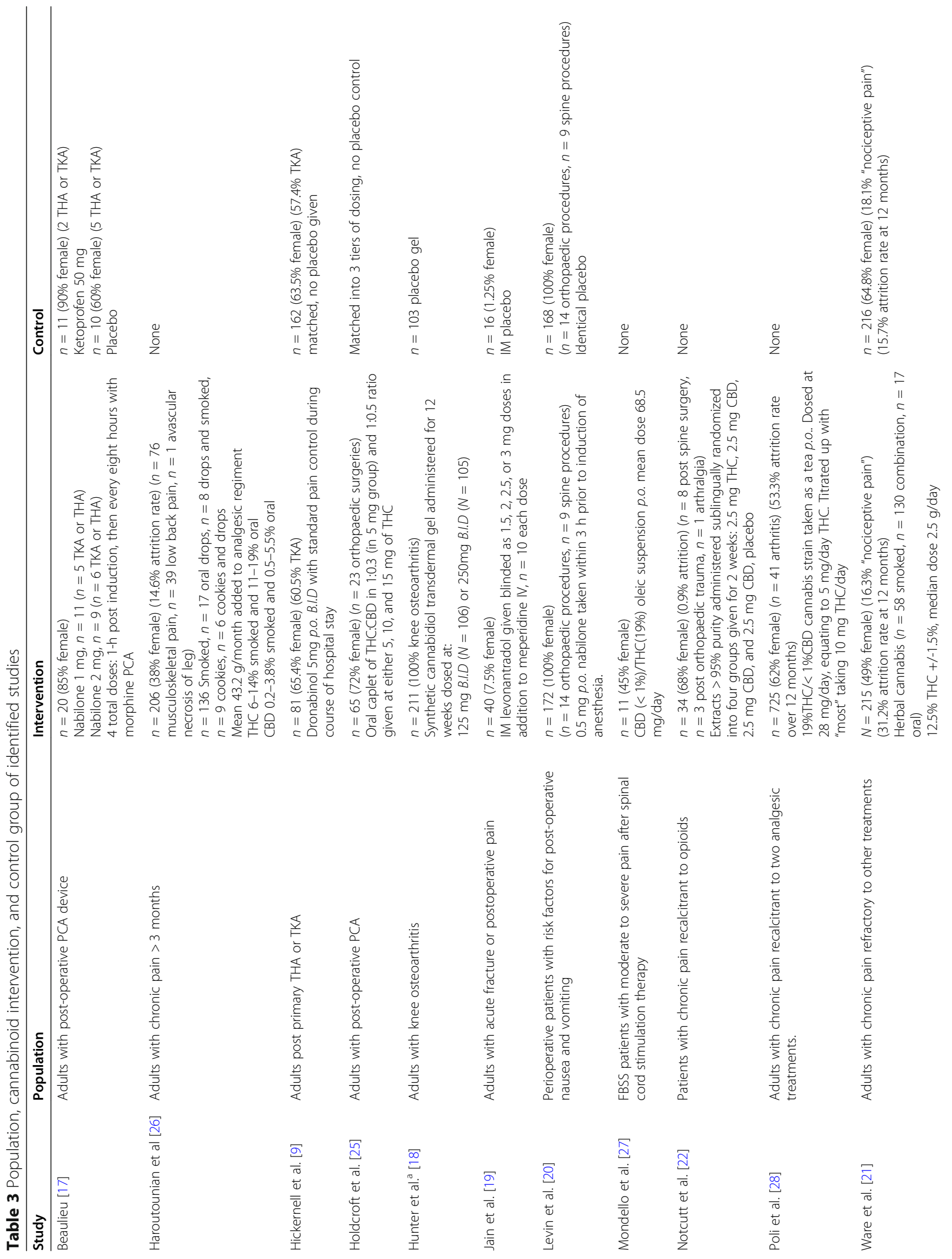




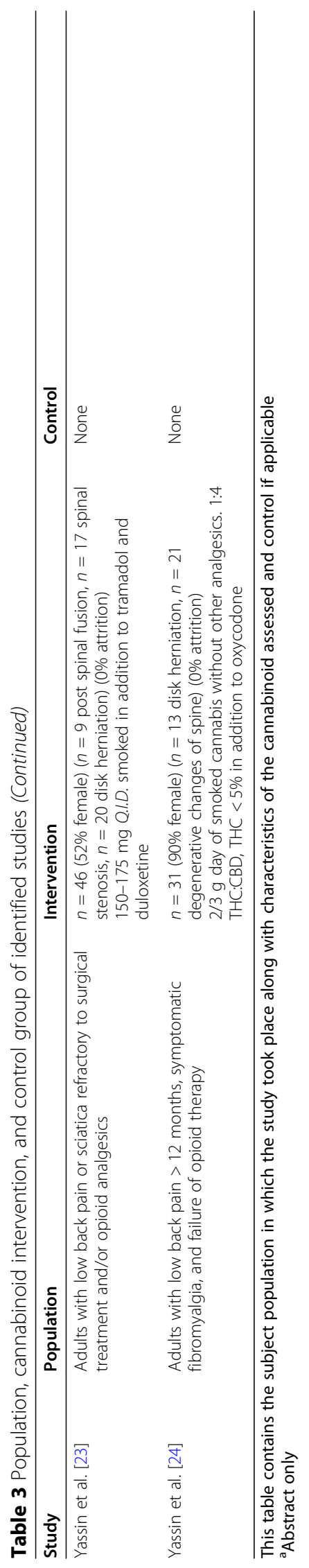




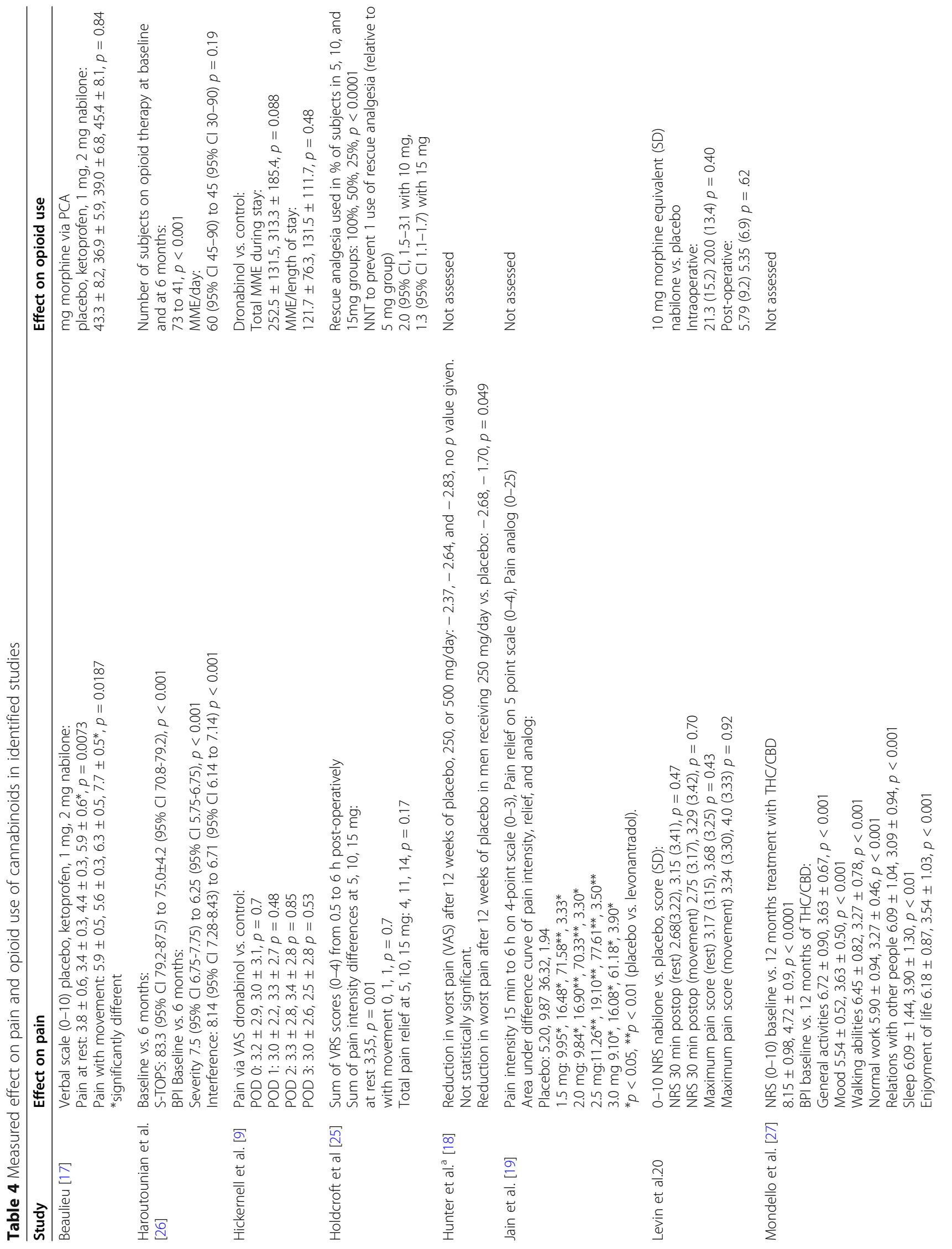




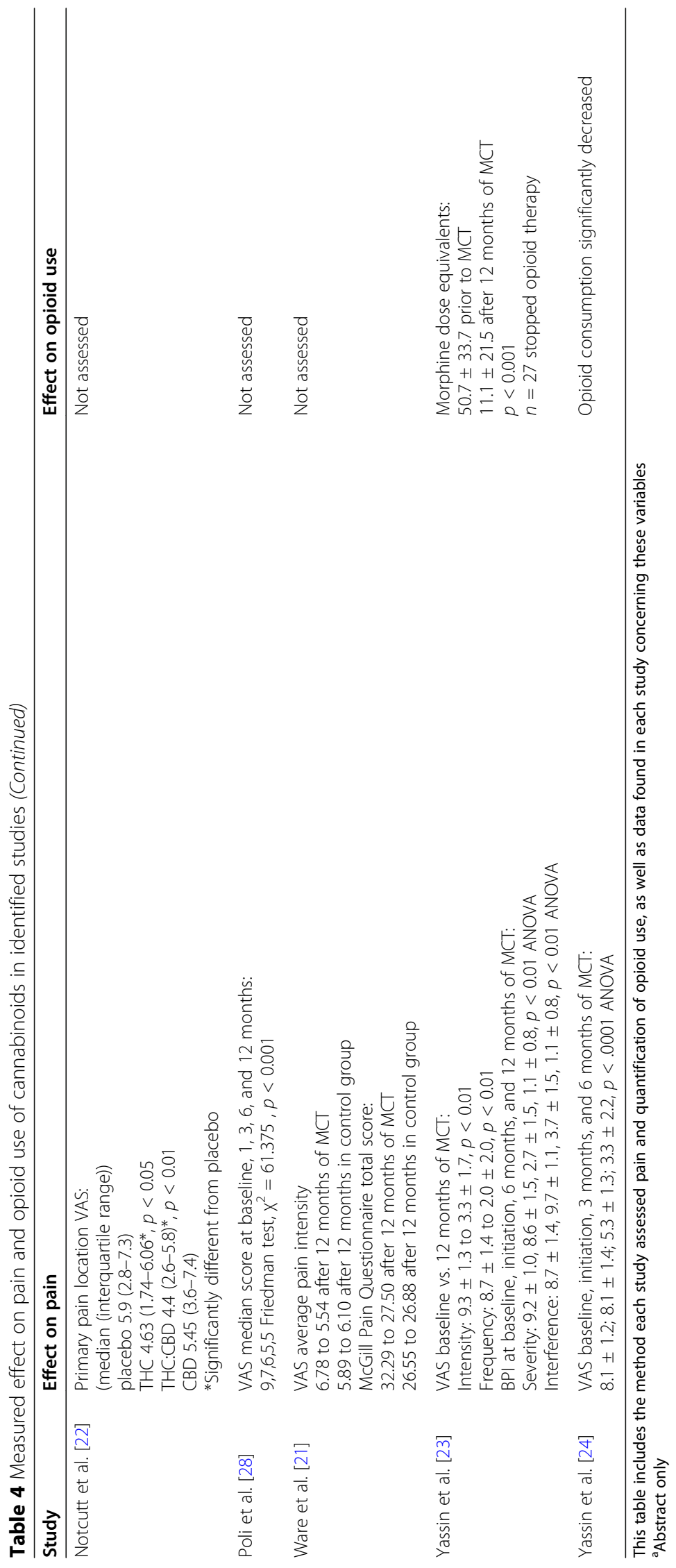


placebo in one study [22]. Three studies [21, 22, 26] sought changes in hematologic markers; there was only one instance of aberration attributed to the intervention: an increase in transaminases [26]. Two studies ended prematurely: one due to a vasovagal event [25] and another due to a paradoxical worsening of pain [17] (Table 5).

\section{Discussion}

The therapeutic application of cannabinoids is an emerging area of research. While Madden et al. focused on study methodology in their reviews appraising the literature through $2017[8,29]$, new studies have since been published [9, 18, 24, 27]. In addition to evaluating these new studies, we sought to narrow the focus of our review to analgesic and opioid-sparing effects of cannabinoids within orthopedic surgery.

The importance of investigation into supplemental analgesics is underscored by the current opioid epidemic in the USA, where nearly $10,000,000$ people misused prescription opioids [10] and over 40,000 died of overdose in 2018 [30]. Among all opioid prescriptions, 5.8\% [31] to $7.7 \%$ [32] were written by orthopedic surgeons, indicating that the field is not immune to the growing opioid problem [33]. While useful for post-operative pain, several studies have demonstrated an alarming trend of use long after convalescence from the index surgery [34-36], even among opioid-naïve patients [3739]. This trend may be amplified in the future by the projected growth of orthopedic procedures; the number of TKA and THAs are estimated to quadruple from 2010 to 2030 [40]. The neuropharmacology of cannabinoids regarding nociception [41] make them a promising adjunctive analgesic that could potentially mitigate the need for opioids.

The RCTs included in this review demonstrated mixed efficacy regarding pain [17-20], ranging from effective [19] to anti-analgesic [17]. Hunter et al. noted only a significant reduction in pain among men [18]. Notably,

Table 5 Adverse events recorded in identified studies

\begin{tabular}{|c|c|}
\hline Study & Adverse events \\
\hline Beaulieu [17] & $\begin{array}{l}2 \text { mg nabilone: increased sedation and pain } \\
\text { Xerostomia, nausea, vomiting, respiratory depression, pruritis common but not different between groups }\end{array}$ \\
\hline Haroutounian et al. [26] & $\begin{array}{l}\text { Mild-moderate: } n=9 \text { (sedation, heaviness, decreased concentration) } \\
\text { Severe: } n=2 \text { (increased transaminases and acute confusion) }\end{array}$ \\
\hline Hickernell et al. [9] & None during length of hospital course (mean 2.3-3 days) \\
\hline Holdcroft et al. [25] & $\begin{array}{l}\text { \% of } 5,10,15 \mathrm{mg} \text { subjects experiencing adverse events: } 9 \%, 30 \%, 50 \%, p=0.002 \\
n=4 \text { dizziness, } n=4 \text { dysphoria, } n=2 \text { xerostomia, } n=2 \text { paranoia, } n=2 \text { pallor, } n=2 \text { tachycardia, } n=1 \text { pyrexia, } \\
n=1 \text { vomiting, } n=1 \text { sensory change, } n=1 \text { sleep disturbance, } n=1 \text { vasovagal syncope } \\
\text { Change in sedation VRS (0-4) at } 5,10 \text {, and } 15 \mathrm{mg:} 0,-2,-3, p=0.03\end{array}$ \\
\hline Hunter et al. ${ }^{a}[18]$ & Application site xerosis (3.8 vs. 0.9\%) and headache (3.3\% vs. 1.9\%) were greater than placebo \\
\hline Jain et al .[19] & $\begin{array}{l}2 \text { events with placebo vs. } 53 \text { with levonantradol. Most commonly } n=19 \text { sedation, } n=5 \text { xerostomia, } n=4 \text { dizziness, } \\
\text { and } n=3 \text { weird dreams. } \\
\text { No discontinuation, no dose dependent response }\end{array}$ \\
\hline Levin et al. [20] & $\begin{array}{l}\text { Lack of muscle coordination nabilone vs. placebo: } 3 / 172 \text { vs. } 0 / 168, p<0.0001 \\
\text { No other significant difference in adverse events, other common events: } n=31 \text { xerostomia, } n=13 \text { headache, } n=5 \\
\text { drowsiness }\end{array}$ \\
\hline Mondello et al. [27] & $\begin{array}{l}n=4 \text { drowsiness, } n=3 \text {, decreased concentration, } n=2 \text { xerostomia, } n=2 \text { headache, } n=2 \text { nausea/vomiting, } n=1 \text { apathy, } \\
n=1 \text { puffy lips, } n=1 \text { palpitations, } n=1 \text { dizziness, } n=1 \text { dysmorphic sensation, } n=1 \text { mood disorder, } n=1 \text { forgetfulness, } \\
n=1 \text { urinary retention. }\end{array}$ \\
\hline Notcutt et al. [22] & $\begin{array}{l}\text { CBD:THC run-in } n=21 \text { xerostomia, } n=23 \text { drowsiness, } n=18 \text { dys/euphoria } \\
\text { THC:CBD }: n=20 \text { xerostomia, } n=14 \text { drowsiness, } n=12 \text { dys/euphoria } \\
\text { THC: } n=17 \text { xerostomia, } n=20 \text { drowsiness, } n=12 \text { dys/euphoria } \\
\text { CBB: } n=15 \text { xerostomia, } n=8 \text { drowsiness, } n=4 \text { dys/euphoria } \\
\text { placebo: } n=11 \text { xerostomia, } n=7 \text { drowsiness, } n=1 \text { dys/euphoria } \\
n=1 \text { vasovagal syncope with THC }\end{array}$ \\
\hline Poli et al. [28] & $\begin{array}{l}n=8 \text { confusion, } n=6 \text { drowsiness, } n=3 \text { worsening pain, } n=3 \text { tachycardia, } n=3 \text { anxiety, } n=3 \text { hallucinations, } n=2 \text { pruritis, } \\
n=1 \text { depression, } n=1 \text { nausea, } n=1 \text { increased appetite, } n=1 \text { diarrhea, } n=1 \text { anal burning, } n=1 \text { depression, } n=1 \text { dizziness }\end{array}$ \\
\hline Ware et al. [21] & $\begin{array}{l}\text { Serious events } 40 \text { with MCT vs. } 56 \text { without MCT at } 12 \text { months, IRR }=0.82 \text { ( } 95 \% \text { Cl 0.46-1.46) } \\
1 \text { severe event deemed likely related to cannabinoids: convulsions } \\
\text { Total non-serious events } 818 \text { with MCT vs. } 581 \text { without MCT at } 12 \text { months, IRR }=1.64(95 \% \mathrm{Cl} 1.35-1.99) \\
\text { Nervous system disorders, respiratory disorders, infections, psychiatric disorders significantly higher in MCT group } \\
\text { Most common: } n=41 \text { headache, } n=37 \text { nasopharyngitis, } n=36 \text { nausea, } n=29 \text { somnolence, } n=27 \text { dizziness, } n=17 \\
\text { vomiting, } n=16 \text { cough, } n=9 \text { euphoria }\end{array}$ \\
\hline Yassin et al. [23] & $n=25$ increased appetite, $n=19$ conjunctival injection \\
\hline Yassin et al. [24] & $n=28$ conjunctival injection, $n=5$ increased appetite, $n=3$ sore throat \\
\hline
\end{tabular}


Levin et al.'s subjects were entirely female [20] and Beaulieu et al.'s nabilone group was comprised of $85 \%$ females [17], while Jain et al. studied $>90 \%$ male subjects [19]. Indeed, the sexual dimorphism of cannabinoid pharmacology has been discussed [42, 43] and a recent review noted differing degrees of analgesia among sexes across nine clinical and preclinical studies [43]. All nine non-RCTs demonstrated a positive analgesic effect. However, these studies were non-randomized and only two had parallel control groups limiting the applicability and generalizability of the findings.

The reduction in opioid use was promising; five of seven studies demonstrated reduced opioid consumption with cannabinoid therapy. Holdcroft el al. noted a dosedependent response in the reduction of rescue analgesia in their trial evaluating post-operative pain [25]. Hickernell et al. reported a reduction in perioperative opioid use; however, this was in the setting of a decreased length of stay in their dronabinol group and no significant change in opioid use per day [9]. A sizeable portion of subjects were able to discontinue opioid therapy at six [26] and twelve [23] months; however, both studies lacked comparative control groups. RCTs evaluating opioid consumption found no difference; however, Levin et al. limited their study to the immediate recovery period within the post anesthesia care unit [20] and Beaulieu et al. limited their study to $24 \mathrm{~h} \mathrm{[17].}$

There was a lack of standardization among dose, frequency, concentration, and route of administration. Caplets of synthetic THC were studied in doses of $0.5 \mathrm{mg}$ taken once [20], $5 \mathrm{mg}$ twice a day throughout the hospital course following the index procedure [9], and $1 \mathrm{mg}$ or 2 mg taken four times within $24 \mathrm{~h} \mathrm{[17].} \mathrm{Levonantradol,} \mathrm{an-}$ other synthetic THC derivative, was administered in 1.5 $\mathrm{mg}, 2 \mathrm{mg}, 2.5 \mathrm{mg}$, and $3 \mathrm{mg}$ aliquots intramuscularly by Jain et al. [19]. Synthetic transdermal CBD was dosed at either $250 \mathrm{mg}$ or $500 \mathrm{mg}$ a day [18]. Natural cannabinoids ranged in concentrations of $<5 \%$ [24] to 95\% [22] THC and $<1 \%$ [28] to $95 \%$ [22] CBD. Oral caplets were dosed 5-15 mg [25], sublingual drops $2.5 \mathrm{mg}$ [22], and oral extractions $28 \mathrm{mg}$ [28] to $68.5 \mathrm{mg}$ [27]. All four studies evaluating smoked cannabis varied in median dose ranging from $600 \mathrm{mg}$ [23] to $2500 \mathrm{mg}$ daily [21].

Cannabinoid choice varied among studies and included synthetic and natural THC, CBD, and THC/CBD combinations. Nottcut et al. demonstrated an increased efficacy of THC and THC/CBD in combination over CBD alone [22]. This finding is also supported elsewhere; a RCT evaluating oncogenic pain found $\mathrm{THC} /$ CBD mixtures were more efficacious than placebo and THC alone [44]. The combination of THC and CBD may be useful. Preclinical research has suggested that CBD can mitigate the neuropsychiatric effects produced by THC $[45,46]$.
Synergism among endogenous cannabinoids [47] has led to the speculation of a similar relationship where THC and CBD may augment the effects of one another when administered synchronously in what has been termed the "entourage effect" [48, 49].

All but one study [9] found AEs. Ware et al. specifically sought to measure AEs primarily with smoked cannabis, noting decreased pulmonary function as well as increased upper respiratory complaints and infections within their cannabis group over the course of 12 months [21]. Smoking was a common route of administration found in this review and many concerns with the combustion of organic plant material exist. Indeed, the deleterious effects of smoked tobacco are well known [50]. Although less studied, cannabis smoke has been associated with negative sequalae such as lung cancer [51] and lower bone mineral densities among heavy users [52].

Among other routes of administration, Hickernell et al. noted no AEs among 81 patients receiving $5 \mathrm{mg}$ dronabinol [9], while studies evaluating nabilone recorded increased rates of impaired muscle coordination [20] and sedation [17] at $0.5 \mathrm{mg}$ and $2 \mathrm{mg}$ respectively. Other common reported effects include nausea, vomiting, altered mentation, and potential drug interactions [4]. Transdermal CBD products are less known in terms of AEs; Hunter et al. found an increased incidence of headache and application site xerosis with this modality vs. placebo [18]. Due to a severe vasovagal event at 15 mg THC/CBD, Holdcroft et al. ceased recruitment in their study. This same study noted a dose-dependent response in AEs from 5 to $15 \mathrm{mg}$ of oral THC/CBD [25]; however, Jain et al. did not demonstrate a dose related response in AEs from 1.5 to $3 \mathrm{mg}$ IM levonantradol [19]. Neuropsychiatric events were rare, consisting mainly of sedation. Euphoria and hallucinations were reported, but rarely. Overall, cannabinoids were welltolerated within this review; however, this is insufficient evidence to fully evaluate the safety of these compounds. Similarly, the stark differences in route of administration, dose, and actual cannabinoid used underscore the lack of standardization in the use of these compounds and create difficulty in comparing their safety and efficacy across the literature.

Among adverse events, the potential for addiction, chronic dependence, and the resultant socioeconomic effects of employing cannabinoids into orthopedic practice are salient concerns that unfortunately were not assessed within the studies included in this review. However, both the benefits and risks of any therapy must be considered. The ravages of opioid addiction are known, summating in tens of thousands of deaths per year in the USA [30]. The ability of cannabinoids to mitigate this crisis outweighs the negative ramifications in the authors' opinion. Indeed, in states of the USA where cannabinoid use 
has become legal, there have been decreased rates of opioid prescriptions, opioid abuse, opioid-associated hospital admissions, and overdose mortality rates [5355]. Cannabinoids are mechanistically different than opioids resulting in key differences [41]. Opioids depress respiratory drive [56] and indeed this is the primary mechanism of death in acute overdose [57]. Contrarily, no fatal overdoses have been reported with medical or recreational cannabinoid use; furthermore, the quantity of cannabinoids needed to induce a potentially fatal overdose is many multitudes beyond the therapeutic dose [58, 59]. Paradoxically, higher doses of cannabinoids have been reported to cause hyperalgesia [60]. This effect may provide a ceiling to the continual upward titration of dosages. The prolonged use of opioids has been associated with hyperalgesia possibly begetting the need for an ever-increasing dosage to adequately address pain [61]. In contrast, cannabinoids have been shown to not induce hyperalgesia with chronic use [62]. The combination of these factors speaks against chronic dependence upon cannabinoids for pain control.

There are several limitations acknowledged within this review. The dearth of literature existing on cannabinoids in orthopedic surgery left few studies to review. Much of our data was extracted from papers where only a fraction of the subjects underwent orthopedic procedures or had orthopedic conditions. It is impossible to know in these studies what the true impact of cannabinoids was on orthopedic patients given the data of all subjects was combined. The heterogeneity of data and methodology made it impossible to perform a meta-analysis. The overall quality of available data also affects this review, given many studies included are either low to very low in quality and only four RCTs met the inclusion criteria.

\section{Conclusion}

There is sparse data regarding the use of cannabinoids in orthopedic surgery. Only two studies in this review had subjects solely within orthopedics $[9,18]$. The applicability of existing RCTs is limited by several factors, chiefly the heterogeneity of intervention and conflicting results. The evidence from non-RCTs demonstrates that cannabinoids may be an effective adjunctive analgesic and possibly curtail opioid usage. However, this is far from convincing, given the overall lack of rigor in their non-randomized design. With exceptions, cannabinoids were well-tolerated within the confines of this review, mainly causing minor AEs. The potential to serve as well tolerated analgesic adjuncts that could mitigate opioid usage make cannabinoids promising agents to investigate. The production of high-quality evidence via well designed RCTs is needed to accurately assess these effects. Attention to route of administration, dosage, choice of cannabinoid, and potential differences in gender response may be important considerations in designing future trials.

\section{Expectations}

It is of the opinion of the authors that cannabinoids may represent an adjunctive solution in providing additional analgesia in an effort to combat the overuse of opioids within orthopedic surgery. Though the current paucity of rigorous evidence makes it difficult to recommend the use of cannabinoids outside of patients involved in research trials. We would expect as legal barriers to studying these compounds continue to dissolve, more research will be performed that will better establish the usefulness of medicinal cannabinoids while better characterizing and refining indications for cannabinoid therapy within orthopedics, dosing, and route of administration. Though impossible to clearly prognosticate, the acceptance of cannabinoids as a legitimate means of pain control could alter prescribing patterns of future orthopedic surgeons and mitigate the current opioid crisis.

\section{Abbreviations}

PRISMA: Preferred Reporting Items for Systematic Reviews and MetaAnalyses; U.S.: United States of America; FDA: U.S. Food and Drug Administration; THC: Delta-9-tetrahydrocannabinol; CBD: Cannabidiol; AE: Adverse events; GRADE: Grading of Recommendations of Assessment, Development, and Evaluation; RoB 2: Revised Cochrane risk-of-bias tool for randomized trials; RCTs: Randomized controlled trials; ROBINS-I: The Risk of Bias In Non-Randomized Studies-of Interventions; BPI: Brief Pain Index; TLE: Therapeutic level of evidence; M: Moderate; L: Low; VL: Very low; SC: Some concern; PCA: Patient controlled anesthesia; THA: Total hip arthroplasty; TKA: Total knee arthroplasty; ASA: American Society of Anesthesiologist's scale; B.I.D.: Bis in die; p.o: Per os; IM: Intramuscular; IV: Intravenous; FBBS: Failed back surgery syndrome; Q.I.D.: Quater in die; VAS: Visual analogue scale; MME: Milligram morphine equivalent; VRS: Verbal rating scale; NNT: Numbers needed to treat; S-TOPS: Treatment outcomes in pain survey; POD: Post-operative day; NRS: Numeric rating scale;

MCT: Medical cannabis therapy; OR: Odds ratio; Cl: Confidence interval; IRR: Incidence rate ratio

\section{Acknowledgements}

Not applicable.

\section{Authors' contributions}

BJV wrote the first and all subsequent drafts of the manuscript. BJV and ANS co-created the search algorithm, perused the literature, evaluated the selected studies for inclusion/exclusion, organized and interpreted the findings, formatted the materials for submission, edited the manuscript and materials, and ultimately submitted the work on behalf of all coauthors. Both LYC and SDG were responsible for overseeing the creation of this work, evaluating the quality of the work performed by the junior authors, and providing edits and revisions. Both $J L L$ and $J L G$ were the senior authors responsible for the conception of the project, deciding on the included studies if BJV and ANS disagreed on inclusion/exclusion, providing edits for revisions, and overall supervising the quality and veracity of the created work. The authors read and approved the final manuscript.

\section{Funding}

This study received no means of outside funding.

Availability of data and materials

The data used during this current study is available from the corresponding author on reasonable request. All included data were extracted from articles that are cited here-in and are available at their respective sources. 


\section{Ethics approval and consent to participate}

Not applicable.

\section{Consent for publication}

Not applicable.

\section{Competing interests}

There are no financial or industry relationships of the authors that are construed to be a conflict of interest in relation to the content of this manuscript. The study itself was unfunded, and access to the utilized search databases was provided by the University of Louisville School of Medicine. These resources are freely available to all students and faculty of this institution; both BJV and ANS are students of this institution. For complete transparency, a full statement of disclosure of each author is found below. BJV and ANS have no disclosures.

SDG has consulting roles with Medtronic and K2M/Stryker; has patents with and receives royalties from Medtronic; has database funding with NuVasive; is an employee of Norton Healthcare; is the past president of Scoliosis Research Society; and is the chair of American Spine Registry. LYC is an employee of Norton Healthcare and receives salary from the University of Southern Denmark; receives consulting fees from the National Spine Health Foundation; is a member of the University of Louisville Institutional Review Board; and is on the Editorial Advisory Board of Spine, The Spine Journal and Spine Deformity.

JLL has consulting roles with Stryker/K2M, NuVasive, 4Webb, Spineart, Evolution Spine, and Gerson Lehrman Group; receives royalties from Spineart, Evolution Spine; has intellectual property with Combination biologic and ICBG/BMAC system; receives grants from Medtronic, NuVasive, Stryker/K2M, Orthopaedic Science Research Foundation; receives travel and accommodations from American Institute of Minimally Invasive Surgery, NuVasive, Stryker/K2M, Spineart, Fisher Owen Fund; and serves on the editorial board of Spine, Global Spine Journal, and Journal of Spine Surgery. JLG has consulting roles with Medtronic, Acuity, K2M/Stryker, NuVasive, Mazor; serves in an advisory role to K2/M and Medtronic; receives research support from Integra, Intellirod Spine Incorporated, and Pfizer; had data base privileges with NuVasive; receives royalties Acuity; is on the speaker bureau for Dupuy; has patents with Medtronic; and owns stock with Cingulate Therapeutics.

Institutions which are associated with $L Y C, S D G$, JLL, and JLG receive research funds from Orthopaedic Research and Education Foundation, National Institute of Health, International Spine Study Group, Scoliosis Research Society, Pfizer, Lifesciences Corporation, IntelliRod, Cerapedics, Medtronic, Empirical Spine, and NeuroPoint Alliance.

Received: 16 December 2020 Accepted: 4 January 2021

Published online: 14 January 2021

\section{References}

1. Henson K. State Medical Marijuana Laws Denver, Colorado: National Conference of State Legislature; 2019 [updated October 16, 2019. Available from: https://www.ncsl.org/research/health/state-medical-marijuana-laws. aspx.

2. Medical cannabis [Internet]. National Library of Medicine (U.S.). 2020 [cited 3/25/2020]. Available from: https://pubmed.ncbi.nlm.nih.gov/?term= medical+cannabis\&filter=years.2015-2020\&timeline=expanded.

3. Valeant Pharmaceuticals International. Cesamet (nabilone) [package insert] U.S, Food and Drug Administration website. https://www.accessdata.fda. gov/drugsatfda_docs/label/2006/018677s011lbl.pdf. Revised May 2006. Accessed Febuary 15, 2020.

4. AbbVie Inc.. Marinol (dronabinol)[package insert]. U.S. Food and Drug Administration website. https://www.accessdata.fda.gov/drugsatfda_docs/ label/2017/018651s029lbl.pdf. Revised August 2017. Accessed Febuary 15, 2020.

5. Greenwich Biosciences, Inc.. Epidiolex (cannabidiol) [package insert]. U.S. Food and Drug Administration website. https://www.accessdata.fda.gov/ drugsatfda_docs/label/2018/210365lbl.pdf. Revised June 2018. Accessed Febuary 15, 2020.

6. GW Pharma, Ltd. Sativex (delta-9-tetrahydrobcannabinol and cannabidiol) [package insert] Health Canada website. https://pdf.hres.ca/dpd_pm/ 00016162.PDF. Revised March 2012. Accessed 15 Feb 2020.
7. Whiting PF, Wolff RF, Deshpande S, Di Nisio M, Duffy S, Hernandez AV, et al. Cannabinoids for medical use: a systematic review and meta-analysis. Jama. 2015;313(24):2456-73.

8. Madden K, George A, van der Hoek NJ, Borim FM, Mammen G, Bhandari M. Cannabis for pain in orthopedics: a systematic review focusing on study methodology. Can J Surg. 2019;62(6):369-80.

9. Hickernell TR, Lakra A, Berg A, Cooper HJ, Geller JA, Shah RP. Should cannabinoids be added to multimodal pain regimens after Total hip and knee Arthroplasty? J Arthroplasty. 2018;33(12):3637-41.

10. Substance Abuse and Mental Health Services Administration. Key substance use and mental health indicators in the United States: results from the 2018 National Survey on drug use and health (HHS publication no. PEP19-5068, NSDUH series H-54). Rockville: Center for Behavioral Health Statistics and Quality, Substance Abuse and Mental Health Services Administration; 2019. Retrieved from https://www.samhsa.gov/data/

11. Jones J, Saad L. Gallup poll social series: consumption habitsIn: Service GN, editor; 2019.

12. Moher D, Liberati A, Tetzlaff J, Altman DG, Group P. Preferred reporting items for systematic reviews and meta-analyses: the PRISMA statement. PLoS Med. 2009;6(7):e1000097.

13. Atkins $D$, Best D, Briss PA, Eccles M, Falck-Ytter Y, Flottorp S, et al. Grading quality of evidence and strength of recommendations. BMJ. 2004;328(7454): 1490.

14. Marx RG, Wilson SM, Swiontkowski MF. Updating the assignment of levels of evidence. J Bone Joint Surg Am. 2015;97(1):1-2.

15. Sterne JAC, Savovic J, Page MJ, Elbers RG, Blencowe NS, Boutron I, et al. RoB 2: a revised tool for assessing risk of bias in randomised trials. BMJ. 2019;366: 14898.

16. Sterne JA, Hernan MA, Reeves BC, Savovic J, Berkman ND, Viswanathan M, et al. ROBINS-I: a tool for assessing risk of bias in non-randomised studies of interventions. BMJ. 2016;355:i4919.

17. Beaulieu P. Effects of nabilone, a synthetic cannabinoid, on postoperative pain. Can J Anaesth. 2006;53(8):769-75.

18. Hunter D, Oldfield G, Tich N, Messenheimer J, Sebree T. Synthetic transdermal cannabidiol for the treatment of knee pain due to osteoarthritis. Osteoarthr Cartil. 2018;26:1.

19. Jain AK, Ryan JR, McMahon FG, Smith G. Evaluation of intramuscular levonantradol and placebo in acute postoperative pain. J Clin Pharmacol. 1981;21(S1):320S-6S

20. Levin DN, Dulberg Z, Chan AW, Hare GM, Mazer CD, Hong A. A randomized-controlled trial of nabilone for the prevention of acute postoperative nausea and vomiting in elective surgery. Can J Anaesth. 2017; 64(4):385-95.

21. Ware MA, Wang T, Shapiro S, Collet JP. Team Cs. Cannabis for the management of pain: assessment of safety study (COMPASS). J Pain. 2015; 16(12):1233-42.

22. Notcutt W, Price M, Miller R, Newport S, Phillips C, Simmons S, et al. Initial experiences with medicinal extracts of cannabis for chronic pain: results from 34 'N of 1' studies. Anaesthesia. 2004;59(5):440-52.

23. Yassin M, Garti A, Robinson D. Effect of medicinal cannabis therapy (MCT) on severity of chronic low back pain, sciatica and lumbar range of motion. Int J Anesthesiol Pain Med. 2016;2(1):5. https://doi.org/10.21767/2471-982X.100014.

24. Yassin M, Oron A, Robinson D. Effect of adding medical cannabis to analgesic treatment in patients with low back pain related to fibromyalgia: an observational cross-over single Centre study. Clin Exp Rheumatol. 2019; 37 Suppl 116(1):13-20.

25. Holdcroft A, Maze M, Dore C, Tebbs S, Thompson S. A multicenter doseescalation study of the analgesic and adverse effects of an oral cannabis extract (Cannador) for postoperative pain management. Anesthesiology. 2006;104(5):1040-6.

26. Haroutounian S, Ratz Y, Ginosar Y, Furmanov K, Saifi F, Meidan R, et al. The effect of medicinal cannabis on pain and quality-of-life outcomes in chronic pain: a prospective open-label study. Clin J Pain. 2016;32(12):1036-43.

27. Mondello E, Quattrone D, Cardia L, Bova G, Mallamace R, Barbagallo AA, et al. Cannabinoids and spinal cord stimulation for the treatment of failed back surgery syndrome refractory pain. J Pain Res. 2018;11:1761-7.

28. Poli P, Salvadori C, Avolio S, Valenti I. Medical cannabis in patients with chronic pain; effect on symptom releif and quality of life. An observational study39 Congresso Nazionale Associazione Italiana per lo Studio del Dolore; May 26-28 2016. Rome: Associazione Italiana per lo Studio del Dolore; 2016. p. 24-39. 
29. Madden K, van der Hoek N, Chona S, George A, Dalchand T, Baldawi H, et al. Cannabinoids in the management of musculoskeletal pain: a critical review of the evidence. JBJS Rev. 2018;6(5):e7.

30. Wilson N, Karissa M, Puja S, Smith H, Davis N. Drug and opioid-involved overdose deaths_-United States, 2017-2018. In: Prevention CfDCa, editor. Atlanta: Center for Disease Control and Prevention; 2020. p. 290-7.

31. Guy GP Jr, Zhang K. Opioid prescribing by specialty and volume in the U.S. Am J Prev Med. 2018;55(5):e153-e5

32. Volkow ND, McLellan TA, Cotto JH, Karithanom M, Weiss SR. Characteristics of opioid prescriptions in 2009. Jama. 2011;305(13):1299-301.

33. Morris BJ, Mir HR. The opioid epidemic: impact on orthopaedic surgery. J Am Acad Orthop Surg. 2015;23(5):267-71.

34. Zarling BJ, Yokhana SS, Herzog DT, Markel DC. Preoperative and postoperative opiate use by the arthroplasty patient. J Arthroplasty. 2016; 31(10):2081-4

35. Rozell JC, Courtney PM, Dattilo JR, Wu CH, Lee GC. Preoperative opiate use independently predicts narcotic consumption and complications after total joint arthroplasty. J Arthroplasty. 2017;32(9):2658-62.

36. Orfield NJ, Gaddis A, Russell KB, Hartman DW, Apel PJ, Mierisch C. New long-term opioid prescription-filling behavior arising in the 15 months after orthopaedic surgery. J Bone Joint Surg Am. 2020;102(4):332-9.

37. Dunn LK, Yerra S, Fang S, Hanak MF, Leibowitz MK, Tsang S, et al. Incidence and risk factors for chronic postoperative opioid use after major spine surgery: a cross-sectional study with longitudinal outcome. Anesth Analg. 2018;127(1):247-54.

38. Politzer CS, Kildow BJ, Goltz DE, Green CL, Bolognesi MP, Seyler TM. Trends in opioid utilization before and after total knee arthroplasty. J Arthroplasty. 2018;33(7S):S147-S53 e1

39. Sun EC, Darnall BD, Baker LC, Mackey S. Incidence of and risk factors for chronic opioid use among opioid-naive patients in the postoperative period. JAMA Intern Med. 2016;176(9):1286-93.

40. Kurtz S, Ong K, Lau E, Mowat F, Halpern M. Projections of primary and revision hip and knee arthroplasty in the United States from 2005 to 2030. J Bone Joint Surg Am. 2007;89(4):780-5.

41. Cohen K, Weizman A, Weinstein A. Modulatory effects of cannabinoids on brain neurotransmission. Eur J Neurosci. 2019;50(3):2322-45.

42. Fattore L, Fratta W. How important are sex differences in cannabinoid action? Br J Pharmacol. 2010;160(3):544-8.

43. Cooper ZD, Craft RM. Sex-dependent effects of cannabis and cannabinoids: a translational perspective. Neuropsychopharmacology. 2018;43(1):34-51.

44. Johnson JR, Burnell-Nugent M, Lossignol D, Ganae-Motan ED, Potts R, Fallon MT. Multicenter, double-blind, randomized, placebo-controlled, parallelgroup study of the efficacy, safety, and tolerability of THC:CBD extract and THC extract in patients with intractable cancer-related pain. J Pain Symptom Manage. 2010;39(2):167-79

45. Niesink RJ, van Laar MW. Does cannabidiol protect against adverse psychological effects of THC? Front Psych. 2013;4:130.

46. Hudson R, Renard J, Norris C, Rushlow WJ, Laviolette SR. Cannabidiol counteracts the psychotropic side-effects of delta-9-tetrahydrocannabinol in the ventral hippocampus through bidirectional control of ERK1-2 phosphorylation. J Neurosci. 2019;39(44):8762-77.

47. Ben-Shabat S, Fride E, Sheskin T, Tamiri T, Rhee MH, Vogel Z, et al. An entourage effect: inactive endogenous fatty acid glycerol esters enhance 2arachidonoyl-glycerol cannabinoid activity. Eur J Pharmacol. 1998;353(1):2331.

48. Russo E, Guy GW. A tale of two cannabinoids: the therapeutic rationale for combining tetrahydrocannabinol and cannabidiol. Med Hypotheses. 2006; 66(2):234-46.

49. Russo EB. Taming THC: potential cannabis synergy and phytocannabinoidterpenoid entourage effects. Br J Pharmacol. 2011;163(7):1344-64.

50. Yanbaeva DG, Dentener MA, Creutzberg EC, Wesseling G, Wouters EF. Systemic effects of smoking. Chest. 2007;131(5):1557-66.

51. Aldington $S$, Harwood M, Cox B, Weatherall M, Beckert $L$, Hansell $A$, et al. Cannabis use and risk of lung cancer: a case-control study. Eur Respir J. 2008;31(2):280-6.

52. Sophocleous A, Robertson R, Ferreira NB, McKenzie J, Fraser WD, Ralston SH. Heavy cannabis use is associated with low bone mineral density and an increased risk of fractures. Am J Med. 2017;130(2):214-21.

53. Shi Y. Medical marijuana policies and hospitalizations related to marijuana and opioid pain reliever. Drug Alcohol Depend. 2017;173:144-50.
54. Shi Y, Liang D, Bao Y, An R, Wallace MS, Grant I. Recreational marijuana legalization and prescription opioids received by Medicaid enrollees. Drug Alcohol Depend. 2019;194:13-9.

55. Bachhuber MA, Saloner B, Cunningham CO, Barry CL. Medical cannabis laws and opioid analgesic overdose mortality in the United States, 1999-2010. JAMA Intern Med. 2014;174(10):1668-73.

56. Pattinson KT. Opioids and the control of respiration. Br J Anaesth. 2008; 100(6):747-58.

57. White JM, Irvine RJ. Mechanisms of fatal opioid overdose. Addiction. 1999; 94(7):961-72.

58. Gable RS. Toward a comparative overview of dependence potential and acute toxicity of psychoactive substances used nonmedically. Am J Drug Alcohol Abuse. 1993;19(3):263-81.

59. Lachenmeier DW, Rehm J. Comparative risk assessment of alcohol, tobacco, cannabis and other illicit drugs using the margin of exposure approach. Sci Rep. 2015;5:8126.

60. Wallace $M$, Schulteis $G$, Atkinson JH, Wolfson T, Lazzaretto D, Bentley $H$, et al. Dose-dependent effects of smoked cannabis on capsaicin-induced pain and hyperalgesia in healthy volunteers. Anesthesiology. 2007;107(5): 785-96.

61. Angst MS, Clark JD. Opioid-induced hyperalgesia: a qualitative systematic review. Anesthesiology. 2006:104(3):570-87.

62. St Pierre $M$, Russo EB, Walsh $Z$. No evidence of altered reactivity to experimentally induced pain among regular cannabis users. Clin J Pain. 2020;36(8):589-93.

\section{Publisher's Note}

Springer Nature remains neutral with regard to jurisdictional claims in published maps and institutional affiliations.

Ready to submit your research? Choose BMC and benefit from:

- fast, convenient online submission

- thorough peer review by experienced researchers in your field

- rapid publication on acceptance

- support for research data, including large and complex data types

- gold Open Access which fosters wider collaboration and increased citations

- maximum visibility for your research: over $100 \mathrm{M}$ website views per year

At BMC, research is always in progress.

Learn more biomedcentral.com/submissions 